Hydrology and Earth System Sciences, 6(4), 709-720 (2002) C $\quad$ EGS

\title{
A new approach to estimating Mean Flow in the UK
}

\author{
M.G.R. Holmes ${ }^{1}$, A.R.Young ${ }^{1}$, A. Gustard ${ }^{1}$ and R. Grew ${ }^{2}$ \\ ${ }^{1}$ Natural Environment Research Council, Centre for Ecology and Hydrology, Wallingford, Oxfordshire, OX10 8BB, UK \\ ${ }^{2}$ Environment Agency for England and Wales, South West Region, Exeter, EX2 7LQ, UK \\ Email for corresponding author: mgrh@ceh.ac.uk
}

\begin{abstract}
Traditionally, the estimation of Mean Flow (MF) in ungauged catchments has been approached using conceptual water balance models or empirical formulae relating climatic inputs to stream flow. In the UK, these types of models have difficulty in predicting MF in low rainfall areas because the conceptualisation of soil moisture behaviour and its relationship with evaporation rates used is rather simplistic. However, it is in these dry regions where the accurate estimation of flows is most critical to effective management of a scarce resource. A novel approach to estimating MF, specifically designed to improve estimation of runoff in dry catchments, has been developed using a regionalisation of the Penman drying curve theory. The dynamic water balance style Daily Soil Moisture Accounting (DSMA) model operates at a daily time step, using inputs of precipitation and potential evaporation and simulates the development of soil moisture deficits explicitly. The model has been calibrated using measured MFs from a large data set of catchments in the United Kingdom. The performance of the DSMA model is superior to existing established steady state and dynamic water-balance models over the entire data set considered and the largest improvement is observed in very low rainfall catchments. It is concluded that the performance of all models in high rainfall areas is likely to be limited by the spatial representation of rainfall.
\end{abstract}

Keywords: hydrological models, regionalisation, water resources, mean flow, runoff, water balance, Penman drying curve, soil moisture model

\section{Introduction}

Within water resources, the Mean Flow (MF) of a river is a commonly used statistic which may be calculated from an annual time series of daily flows recorded at a gauging station by taking an arithmetic average of observed flows and provides a preliminary assessment of resource availability in a catchment. MF may be used to standardise flow statistics to minimise the influence of climatic and catchment scale, enabling the impact of other physical or climatic controls on river flows to be investigated. For example, in the UK, strong relationships have been found between low flow statistics standardised by MF and descriptors of catchment hydrogeology (Institute of Hydrology, 1980; Holmes et al., 2002). More recently there has been interest in developing MF models for calibrating general climatic models for simulating climate change scenarios (Russell and Miller, 1990; Arnell, 1999). In practice, water resource assessments are often required in catchments that are ungauged, hence regionalised models for estimating MF at any point within a river network are commonly required.

A useful transformation is to express MF as an equivalent depth of water over the contributing catchment, which is referred to as an Average Annual Runoff Depth (AARD). When transformed in this manner the observed values of runoff in the UK range from over $3500 \mathrm{mmyr}^{-1}$ in the upland areas in western Scotland, to less than $50 \mathrm{mmyr}^{-1}$ in East Anglia. High rainfall in catchments in the west and north of the UK is a consequence of orographically enhanced precipitation associated with westerly depressions, the predominant source of precipitation in the UK, (Shaw, 1988). The spatial heterogeneity in rainfall is also higher within these areas of rapidly varying topographic relief.

Hydrologists estimate flows in the absence of gauge records by physical and/or statistical relationships between flow, climate and catchment characteristics. Modelling methodologies range from simple water balance models for mean flow (Institute of Hydrology, 1980; Gustard et al., 
1992) to complex physically based rainfall runoff models (Moore, 1985; Manley, 1978) designed to replicate the entire observed hydrograph; consequently, they contain many parameters, require suitable calibration in specific catchments and generally are not suited to regionalisation. Mean flow models, in contrast, seek to replicate only one aspect of the observed hydrograph, the measure of central tendency and, hence, are of a simplified form, with few parameters and are suited to regionalisation. Furthermore, mean flow models tend to have lower data requirements in terms of the temporal and spatial resolution of the climatic data, which ultimately assist in the application of the models on a national basis. However, there are disadvantages associated with such simplifications; e.g. the model developed by Gustard et al. (1992) has difficulty predicting MF in very dry catchments due to the simplified model structure.

This study developed a regionalised, nationally applicable water balance type model that addressed current deficiencies in MF estimation in the low rainfall areas of the UK. The model incorporates a soil moisture accounting model and was calibrated against stream flow records for numerous hydrologically representative catchments in the UK. Results were compared with estimates of MF derived from the steady state water balance model developed by Gustard et al. (1992) and the UK Meteorological Office Rainfall and Evaporation Calculation system (MORECS).

\section{Background}

Each of the models considered by this study uses the concept of a catchment water balance, albeit applied at different temporal and spatial scales. The catchment water balance is one of the most fundamental principles in hydrology. A catchment is considered as a closed system generating river flows in response to precipitation inputs, evaporation outputs and changes in the total volume of water stored in the catchment. The general form of a water balance model is Eqn. (1) where $q$ is the river flow per unit area, $P$ is precipitation, $E$ is net evaporative losses and the $\Delta S$ term is the change in storage of water within the catchment.

$$
q=P-E \pm \Delta S
$$

Models based on water balance principles are conceptually appealing as their form includes an understanding of the relationships between the processes controlling flow generation. Application of the water balance equation requires catchment based-estimates of precipitation, evaporation and a measure of the change in storage of water within the catchment. The effect of changes in water storage within a catchment can be minimised by using long modelling periods and excluding catchments susceptible to significant gauge by-pass, such as those with ephemeral streams with very permeable beds.

Precipitation inputs of catchment average rainfall estimates are typically made by interpolating point data recorded at raingauges over the catchment area. This study was restricted to catchments without significant precipitation contributions of snow, typically the case in the UK with the exception of very high elevation areas in Scotland. Although measurement of rainfall is conceptually simple, uncertainties arise from the point measurement of rainfall, the interpolation scheme and the density of the raingauge network used to extrapolate the data to a spatial coverage. Lowland areas of the UK tend to have higher densities of raingauges than the mountainous and inaccessible highlands of Scotland. Consequently, errors of interpolation, likely to be higher in mountainous areas are compounded by the high spatial heterogeneity in rainfall in these areas.

Evaporation from a catchment is dependant on the climatic conditions that provide the required energy to transform water from a liquid to a gas, as transpiration via vegetation and evaporation from free water surfaces and the soil matrix. Consequently, point measurement of evaporation using lysimeters is more complex than measurement of rainfall. Variations in vegetation, soils and climatic conditions across UK catchments are significant, the network of lysimeters is relatively sparse and hence extrapolation and interpolation of the data will introduce uncertainties in the estimation of catchment average evaporation.

Rather than measuring evaporation directly, researchers have developed methods to estimate catchment-scale evaporation using their understanding of the processes involved. Simple methods for estimating evaporation directly from rainfall and air temperature have been proposed by Turc (1954, 1955) and Thornthwaite (1948). Penman (1948) developed the concept of a potential evaporation (PE) rate that represented the maximum evaporation rate from a surface covered with a given vegetation type, supplied with adequate water. Monteith (1965) included a surface resistance term, as a physical representation of water loss from vegetation, to enable PE to be calculated from any surface using the widely accepted Penman-Monteith equation. The advantage of the concept of $\mathrm{PE}$ is that a reference evaporation rate (typically for short grass) can be estimated using meteorological variables of solar radiation or hours of bright sunshine, air temperature and humidity and wind speed or run of wind. However, for calculating catchment water balances, estimates of PE still need to be modified to reflect actual evaporation (AE) rates 
occurring in a catchment.

The relationship between PE and AE is a function of the interaction of soil moisture stores, vegetation and climatic conditions. Penman (1949) conceptualised these physical processes as evaporation taking place at the potential rate when sufficient water is available to satisfy demands made by the plant/soil interface. As the soil moisture store is depleted and soil moisture deficits (SMDs) occur, the net rate of evaporation falls below the potential rate as the vegetation has more difficulty extracting water from the soil and the transpiration process is slowed. Penman (1949) proposed a simple 'drying curve' model that reduced evaporation from the potential rate to a constant actual evaporation rate once a critical 'root reservoir', equivalent to SMD, had been depleted. In this model, the critical SMD level would be defined by a 'root constant', representing the depth of water which could be evaporated readily by a specific vegetation from a specific soil. Grindley (1970) defined root constants for a variety of crop types in the UK and related them to expected maximum SMD values, representing the deficit at which permanent wilting of the vegetation would occur. Deep-rooted vegetation, such as deciduous forests located on permeable soils in southern England, extract water from greater depths than grasses located on thin impermeable soils of the Scottish Highlands.

Alternatives to the 'Penman-Grindley' description of the interaction of soil moisture and evaporation have been suggested. For example, Wallace (1994) argued that the process of correcting estimates of $\mathrm{PE}$, using crop factors for example, to calculate $\mathrm{AE}$ is conceptually complicated and AE should be estimated by identifying the physiological controls on the surface resistance parameter in the PenmanMonteith equation directly. However, many difficulties are associated with quantifying the effect of the environment on surface resistance parameters. Therefore, the PenmanGrindley approach has been incorporated, in modified forms, into deterministic models such as the Four Layer Root Model (FLRM) developed by the Institute of Hydrology, Ragab et al. (1997). This model includes four soil layers between which water can move and assumes a linear reduction in the ratio of $\mathrm{AE}$ to $\mathrm{PE}$ once critical soil moisture conditions are reached. The Meteorological Office Rainfall and Evaporation Calculation System (MORECS) (MORECS v 1.0, Thompson et al., 1981; MORECS v 2.0, Hough et $a l ., 1995)$ represents a national system for producing timeseries of PE estimates using a modified version of the Penman-Monteith equation. Actual evaporation rates are estimated by reducing evaporation from the potential rate in response to daily accrued SMDs. MORECS outputs are in the form of $40 \times 40 \mathrm{~km}$ grids covering the entire UK at a weekly, monthly or annual resolution.
The Penman-Grindley conceptualisation of the interaction of soil moisture and evaporation rates allowed estimates of PE, made at climate stations to be converted to areal estimates of actual evaporation that took account of the variation in vegetation type. This information was originally used by agriculturists to manage crop water requirements more efficiently; however, it also represents a method for estimating water loss from a catchment water balance model. Specifically including a deterministic soil moisture model in water balance type MF models is particularly relevant for areas where the build up of SMDs in summer restricts runoff. Traditional water balance models generally include simple conceptualisations of soil moisture behaviour and hence perform poorly in these regions. Models such as the FLRM and MORECS, calibrated against soil moisture rather than stream flow data, would not be expected to estimate MF well. The inclusion of a simple soil moisture model within a water balance type MF model that is calibrated against stream flow records, can improve MF estimation in low rainfall regions of the UK where the management of water resources is most critical.

\section{Model development}

The Daily Soil Moisture Accounting (DSMA) model developed was suited to estimating MF in very dry catchments since it specifically included a representation of a soil moisture store which would simulate variations in actual evaporation rate. The relationship between evaporation rate and soil moisture was determined using a modified form of the Penman-Grindley model. The constant reduction of $\mathrm{PE}$ to $\mathrm{AE}$ beyond a critical SMD has been replaced with the linear relationship shown in Eqn . (2).

$$
\frac{A E}{P E}=\left[1-\frac{(S M D-R C)}{A \times R C}\right]
$$

where $\mathrm{AE}$ is the actual evaporation rate, $\mathrm{PE}$ is the potential evaporation rate, SMD is the soil moisture deficit, $\mathrm{RC}$ is the rooting constant and $\mathrm{A}$ is the shape parameter.

The shape parameter A effectively determines the maximum SMD after which point evaporation ceases, rather than using the permanent wilting point ascribed by the original model; this introduces greater flexibility into the modelling of soil moisture. The relationships between evaporative rates and soil moisture deficits for the DSMA model and the original Penman-Grindley model are illustrated in Fig. 1. A ground cover of grass has been assumed with a root constant of $75 \mathrm{~mm}$, a permanent wilting point of $125 \mathrm{~mm}$ (Grindley, 1970) and assuming a reduction in evaporation of $75 \%$ once a SMD equivalent to the rooting 


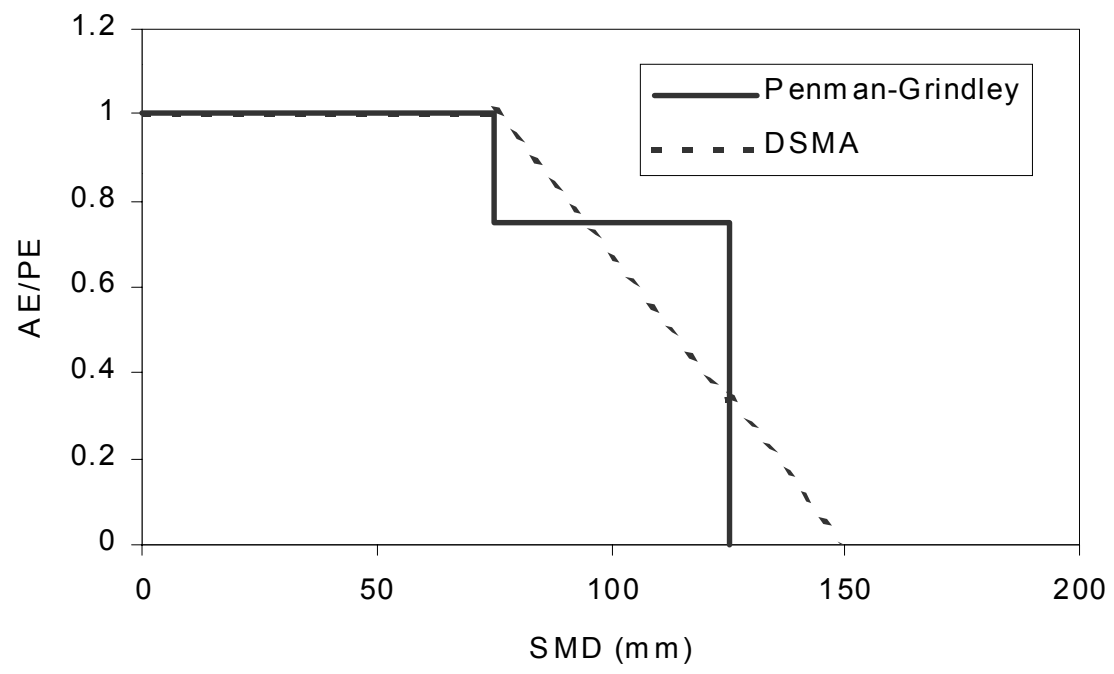

Fig. 1. Relationships between the ratio of actual to potential evaporation in relation to soil moisture deficits proposed by the Penman-Grindley model and the DSMA model (assuming $R C=75 \mathrm{~mm}$ and $A=1$ ) for grass

depth is reached, (Penman, 1949).

The DSMA model conducts a water balance on a daily time step, reflecting the observed time scale at which soil moisture typically varies in UK catchments. Catchment average daily time series of rainfall and potential evaporation were required as inputs and for each time step $i$ the equations governing the generation of runoff and soil moisture deficits are detailed below.

(1) The actual evaporation rate (AE) for time step $i+1$ is governed by whether the existing SMD exceeds the rooting constant ( $\mathrm{RC})$. If $S M D_{i}>R C$ then the evaporation rate is reduced to less than the potential rate following Eqn. 2:

$$
A E_{i+1}=\left[1-\frac{\left(S M D_{i}-R C\right)}{A \times R C}\right] \times P E_{i+1}
$$

If $S M D_{i} \leq R C$ then evaporation occurs at the potential rate:

$$
A E_{i+1}=P E_{i+1}
$$

(2) If sufficient rainfall (R) is occurs within time step $i+1$ to overcome the existing SMD, while satisfying the evaporative demand (AE), then runoff $(\mathrm{RO})$ is generated and the SMD is reset to zero.

$$
\begin{aligned}
& \text { If } R_{i+1}-A E_{i+1}>S M D_{i} \quad \text { then } \\
& R O_{i+1}=R_{i+1}-A E_{i+1}-S M D_{i} \text { and } S M D_{i+1}=0
\end{aligned}
$$

(3) If insufficient rainfall occurs to overcome the existing SMD, while satisfying the evaporative demand, then no runoff is generated and the SMD is increased. If $R_{i+1}-A E_{i+1} \leq S M D_{i}$ then $R O_{i}=0$ and

$$
S M D_{i+1}=R_{i+1}-A E_{i+1}-S M D_{i}
$$

The relatively simple structure of the DSMA was designed deliberately as the model was required only to estimate $\mathrm{MF}$, a single aspect of observed hydrographs, and it is accepted that the model will not predict the whole hydrograph well. Consequently, the inclusion of many parameters would be likely to create problems; Beven (1989), suggested that three to five parameters should be sufficient to describe most aspects of an observed hydrograph. The structure of the DSMA model, Eqn. (2), suggests that a high level of parameter covariance between A and RC could be expected. To avoid the issue of parameter identifiability and model over-specification, the shape parameter A was fixed equal to unity, which effectively dictates that evaporation ceases at twice the rooting constant.

\section{Data}

The climatic inputs for the DSMA model were daily rainfall and potential evaporation grids for the UK, developed at a $1 \times 1 \mathrm{~km}$ resolution, for the period 1961 to 1990 . Digitised catchment boundaries were then overlain to obtain a daily time-series of catchment average estimates of rainfall and potential evaporation.

The grids of daily rainfall were derived from the UK Meteorological Office network of over 6000 rain gauges. The interpolation of point rainfall estimates was undertaken using a modified form of the Triangular Planes method (Jones, 1983) and normalisation by the Met Office Standard period Average Annual Rainfall (SAAR) estimate for the period 1961 to 1990, as described by Young (2000). 
MORECS provides the UK with the only nationally consistent estimates of PE, derived for short grass, using a modified form of the Penman-Monteith equation. These data were available at an average monthly resolution as a $40 \times 40 \mathrm{~km}$ grid. The coarse spatial resolution of the MORECS data is significant at the scale of the catchments in the data set and PE would vary considerably within a given MORECS cell. Therefore, a correction for withincell altitude variations was applied to the monthly MORECS data to refine the data set to a $1 \times 1 \mathrm{~km}$ resolution as described by Young (2000). The PE rate was assumed to be constant for all days within a month.

The DSMA model was calibrated against stream flow data from catchments with essentially natural flow records drawn from the UK National Water Archive (www.ceh.ac.uk/data). A minimum record length of six years was set and the final data set of 677 catchments is shown in Fig. 2, grouped by observed AARD that ranged between $88 \mathrm{~mm} \mathrm{yr}^{-1}$ and $3395 \mathrm{~mm} \mathrm{yr}^{-1}$ (average $657 \mathrm{~mm} \mathrm{yr}^{-1}$, standard deviation $514 \mathrm{~mm} \mathrm{yr}^{-1}$ ).

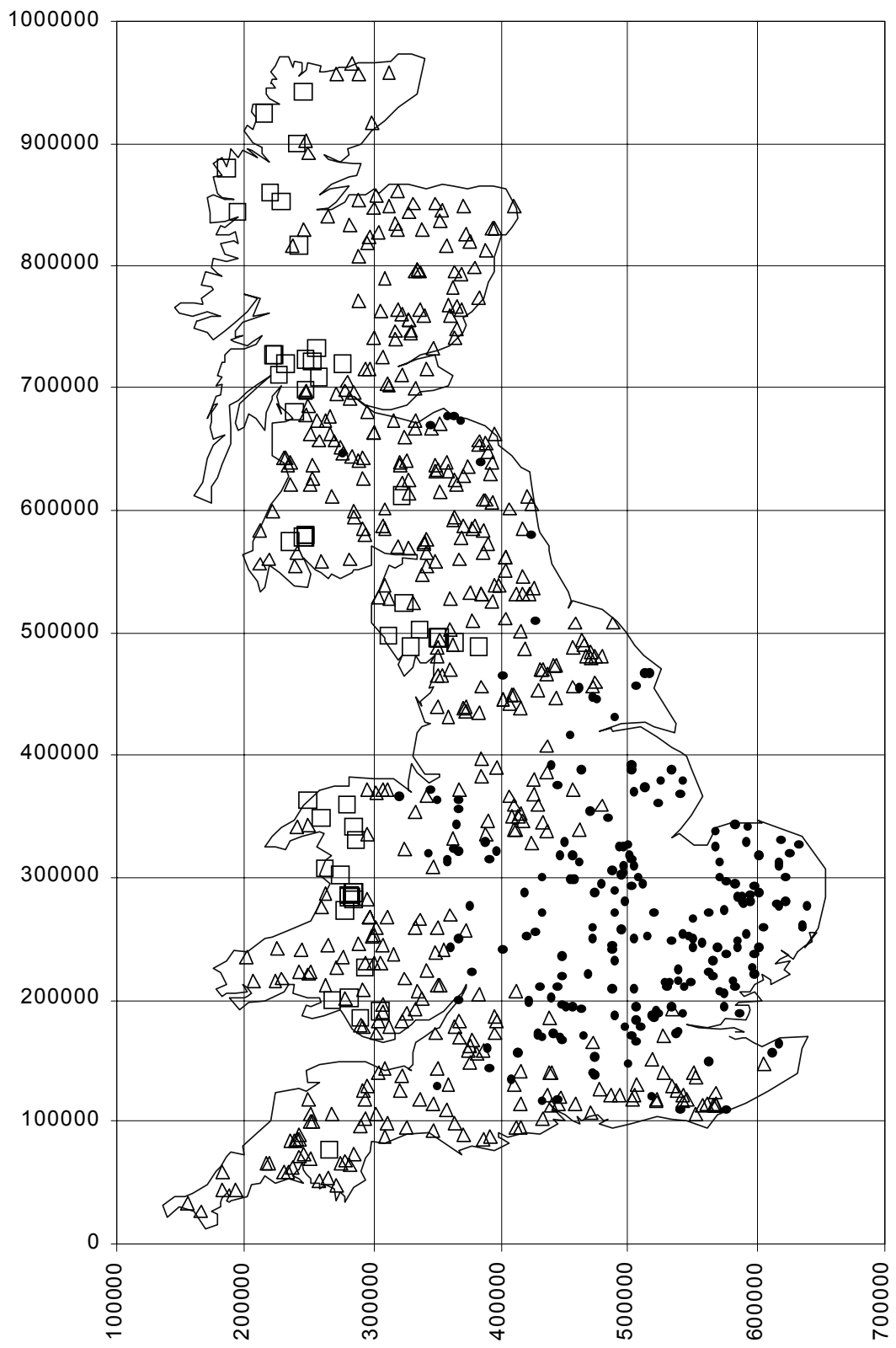

- AARD $<300 \mathrm{~mm} / \mathrm{yr} \triangle 300 \mathrm{~mm} / \mathrm{yr}<\mathrm{AARD}<1500 \mathrm{~mm} / \mathrm{yr} \square \mathrm{AARD}>1500 \mathrm{~mm} / \mathrm{yr}$

Fig. 2. Spatial distribution of catchments grouped by observed average annual runoff depth (AARD) 
The data set was representative of UK catchments in terms of climatic conditions and included a wide range of different hydrological responses. Catchments in the data set recorded values of SAAR ranging between $555 \mathrm{~mm} \mathrm{yr}^{-1}$ and 3473 $\mathrm{mm} \mathrm{yr}^{-1}$ (average $1103 \mathrm{~mm} \mathrm{yr}^{-1}$, standard deviation $482 \mathrm{~mm}$ $\mathrm{yr}^{-1}$ ). The values of average annual PE for the catchment data set ranged between $377 \mathrm{~mm} \mathrm{yr}^{-1}$ and $665 \mathrm{~mm} \mathrm{yr}^{-1}$ (average $536 \mathrm{~mm} \mathrm{yr}^{-1}$, standard deviation $58 \mathrm{~mm} \mathrm{yr}^{-1}$ ).

\section{Optimisation of the Rooting Constant}

The DSMA model was firstly calibrated against observed MF values from streamflow records within the period 1961 to 1990 to identify optimal values of the parameter RC. Catchments likely to violate the assumption of a closed catchment water balance, such as ephemeral permeable catchments, were excluded. Checks were also made to ensure that the start and end date of short flow records (six to ten years) did not fall in drought years, so that any such impact on catchment storage would be minimised and a 'burn in' period of one year would be adequate to establish model stability. Optimal parameter estimates were defined as those that gave the minimum standard residual (SRES);

$$
S R E S=\frac{A A R D_{O B S}-A A R D_{P R E D}}{A A R D_{O B S}}
$$

where $A A R D_{O B S}$ is the observed average annual runoff $\left(\mathrm{mm} \mathrm{yr}^{-1}\right.$ ) and $A A R D_{P R E D}$ is the predicted average annual runoff $\left(\mathrm{mm} \mathrm{yr}^{-1}\right)$ for the catchment. $A A R D_{P R E D}$ values were obtained by averaging the predicted daily values of runoff over the periods for which observed daily values of AARD existed.

Boundary limits of $1 \mathrm{~mm}$ and $250 \mathrm{~mm}$ were adopted for the RC parameter. The lower limit reflects a conceptual lower limit of zero and the upper limit is the maximum rooting depth for permanent woodland on fertile soils suggested by Grindley (1970). These limits were used to identify instances where the conceptual daily water balance was violated. A total of 25 catchments were found to have $\mathrm{RC}_{\text {OPT }}$ values of $1 \mathrm{~mm}$ and 86 catchments had $\mathrm{RC}_{\text {OPT }}$ values of $250 \mathrm{~mm}$. Careful examination revealed that the closed water balance assumption might well have been violated in each case due to errors in the estimation of rainfall (small mountainous catchments), errors in the estimation of catchment area (permeable catchments with non-coincident topographic and groundwater boundaries), or significant artificial influences on the flow regime.

Over the reduced data set of 566 catchments the distribution of $\mathrm{RC}_{\mathrm{OPT}}$ values was positively skewed with a median value of $46 \mathrm{~mm}$. The 10th and 90th percentiles for the distribution were approximately $12 \mathrm{~mm}$ and $107 \mathrm{~mm}$, respectively.

\section{Regionalisation of the Rooting Constant}

A regionalised model for $\mathrm{RC}$ was developed using the optimised rooting constants to enable the model parameter to be determined for any catchment in the UK and hence enable the DSMA to be applied to ungauged catchments. The conceptualisation of the DSMA implies that the RC parameter reflects the ease with which water may be evaporated from the combined soil/vegetation layer. Therefore, the soil and vegetative covers of catchments were used as explanatory variables for regionalising RC.

The Hydrology of Soil Types (HOST) soil classes were used to describe the soil characteristics of a catchment. This classification system, developed by Boorman et al. (1995), groups 969 soil series into 30 HOST classes on the basis of similarity in hydrological response. Physical properties considered to affect hydrological response included soil hydrogeology, depth to aquifer, presence of peaty topsoil, depth to a slowly permeable layer, depth to gleyed layer and integrated air capacity (a surrogate for permeability in permeable soils which indicates the capacity of an impermeable soil to store excess water). The final form of the classification exists as a set of digital grids expressing the fractional extent of each HOST class at a $1 \times 1 \mathrm{~km}$ resolution.

The vegetative characteristics of a catchment were obtained from the LAND classification system, a data set derived from Landsat imagery taken in the early 1990s by the NERC Institute of Terrestrial Ecology (Fuller et al., 1994). This data set defines 26 classes of land use including urban land, arable land, meadows, coniferous forests and deciduous forests. The LAND classification data was converted from a $50 \times 50 \mathrm{~m}$ grid to a $1 \times 1 \mathrm{~km}$ resolution grid of fractional extents of each class.

While Spearman rank correlation analysis confirmed that the fractional extents of HOST and LAND classes within catchments were correlated to $\mathrm{RC}_{\text {OPT, }}$ it also showed significant inter-correlation of these variables. This would be expected since the distribution of vegetation types in the UK generally reflects the underlying soils and climatic conditions. Therefore, a combined classification of LAND and HOST variables (LANDHOST) was developed using progressive stepwise linear regression analysis. Grouping of LAND and HOST variables was required to resolve issues of non-significant parameter estimates relating to poorly represented classes both within the data set and across the UK. The final regression equation included eight groupings 
of LANDHOST variables, see Eqn. (3).

$$
R C_{E S T}=\sum_{i=1}^{8} a_{i} \times \operatorname{LANDHOST}_{i}
$$

where $R C_{E S T}$ is the estimate of the evaporation threshold parameter from the DSMA model; $\mathrm{LANDHOST}_{i}$ is the fraction of the combined LANDHOST class $i$ occurring in the catchment; and $a_{i}$ is a parameter estimate for LANDHOST class $i$.

The final groupings and parameter values shown on Table 1 suggest that $\mathrm{RC}$ is a physically significant parameter reflecting the combined impact of soils and land use/ vegetation on catchment-scale evaporation. The grouping of urban/suburban land use with any soil type (LANDHOST8) confirm that urban land use dominates the evaporation processes regardless of the underlying soil type. Conversely, the groupings in LANDHOST classes 1 to 4 illustrate that the impact of agricultural land use on evaporation will be dependent on the underlying soils. The LANDHOST class representing lakes and bogs was assumed to provide an unlimited supply of water to the evaporation process.

The large uncertainties associated with some of the parameter estimates were regarded as acceptable given the relative scarcity of those classification types within the catchment data set and within the UK.
The performance of the DSMA model, using the regionalised RC parameter values was assessed over the entire data set of catchments. AARD values were derived from averaging the daily runoff values predicted by the DSMA model. The performance of the model was examined over three bands of average annual rainfall; SAAR $<700 \mathrm{~mm} \mathrm{yr}^{-1}$ where significant soil moisture deficits would occur regularly; $700<$ SAAR $<1000 \mathrm{~mm} \mathrm{yr}^{-1}$ and SAAR $>1000 \mathrm{~mm} \mathrm{yr}^{-1}$ where significant soil moisture deficits would not be expected each year.

The performance measures used to assess the ability of a model to predict runoff were BIAS, to assess systematic error and RMSE, to assess random error.

$$
\begin{aligned}
& B I A S=\frac{1}{n} \sum_{i=1}^{n} \frac{A A R D_{O B S}^{i}-A A R D_{P R E D}^{i}}{A A R D_{O B S}^{i}} \\
& R M S E=\sqrt{\frac{1}{n} \sum_{i=1}^{n}\left(A A R D_{O B S}^{i}-A A R D_{P R E D}^{i}\right)^{2}}
\end{aligned}
$$

where $A A R D_{O B S}^{i}$ is the observed value of average annual runoff depth $\left(\mathrm{mm} \mathrm{yr}^{-1}\right)$ for the $i$ th catchment, and $A A R D_{\text {PRED }}^{i}$ is the predicted value of average annual runoff depth $\left(\mathrm{mm} \mathrm{yr}^{-1}\right)$ for the $i$ th catchment.

A factorial standard error (FSE), representing the random error in the predictive capacity of the model, was determined from a logarithmic regression of $\mathrm{AARD}_{\mathrm{OBS}}$ against $\mathrm{AARD}_{\text {PRED }}$.

The performance of the DSMA model was compared, in

\section{Evaluation}

Table 1. Parameter estimates for RC derived using fractional extents of the LANDHOST classification system. Standard error (mm) shown in brackets.

LANDHOST Description
Class

Agricultural land on chalk

Agricultural land on permeable soils

Agricultural land on clays

Agricultural land on rock or peat

Deciduous forest on impermeable clays/rocks/peats

Deciduous forest or Agricultural land on a mixture of soils

Deciduous forest on chalk/permeable soils

Urban, suburban or bare on any soil type

Coniferous forest, grasses/heathers on any soil type

Upland or lowland bogs on any soil type

10

11
Lakes

\section{Percentage of total $R C$ parameter \\ area of catchments estimate \\ covered by Class}

$\begin{array}{ll}7.5 & 83 \\ 11.5 & 56 \\ 15.1 & 69 \\ 8.1 & 56 \\ 2.0 & 164 \\ 20.3 & 51 \\ 1.0 & 375 \\ 4.5 & 19 \\ 29.4 & 18 \\ 0.2 & \text { NA } \\ 0.4 & \text { NA }\end{array}$

$\mathrm{R}^{2}=0.72$ Model Standard Error $=36 \mathrm{~mm}$ 
Table 2, to the performance of three other model approaches to estimating runoff in the UK.

Model A is the steady state water balance model developed by Gustard et al. (1992) and used widely in the UK by environmental regulation agencies, Young et al. (2000). The model is based on average annual climatic variables and has the structure given by Eqn. (4). This model uses a value of average annual rainfall to define the point at which actual evaporation occurs at less than the potential rate. Below this point evaporation takes place at a fraction of the potential rate, defined by a linear relationship with rainfall. Experience has shown that this model has difficulty predicting runoff in the very low rainfall areas of the UK.

Model A:

$$
\begin{aligned}
& \text { where } \quad \mathrm{r}=1 \quad \text { SAAR } \geq 850 \mathrm{~mm} \mathrm{yr}^{-1} \\
& \mathrm{r}=0.475-0.00061 \times \text { SAAR } \quad \text { SAAR }<850 \mathrm{~mm} \mathrm{yr}^{-1}
\end{aligned}
$$

where SAAR is the standard average annual rainfall for the period 1941 to 1970; and PE is the average annual potential evaporation derived from pre-MORECS data sets, mapped isolines at a scale of 1:2 000000 , based on the Penman equation (Penman, 1950) for the same period.

The second model considered is based on MORECS outputs. In addition to PE estimates MORECS estimates hydrologically effective rainfall defined as the rainfall available after soil moisture deficits and evaporation demands have been satisfied, (Hough et al., 1995). Model B simply equates runoff to this estimate of effective rainfall (Eqn. (5)). This model enables comparisons to be made between the relative success of a MORECS's complex semidistributed soil moisture model (calibrated to soil moisture data) and the DSMA model (calibrated against stream flow records) for predicting runoff.

Model B: $\quad A A R D=E R F$

where $E R F$ is the MORECS estimate of average annual

Table 2 . Comparison of the four models

\begin{tabular}{l|l|l|l|l}
\hline \multicolumn{5}{c}{ A } \\
\hline Rainfall data & $\begin{array}{l}\text { Average annual } \\
\text { rainfall interpolated } \\
\text { from the dense } \\
\text { Meteorological } \\
\text { Office network of } \\
\text { raingauges. }\end{array}$ & $\begin{array}{l}\text { Daily rainfall } \\
\text { interpolated from } \\
\text { the reduced } \\
\text { MORECS network } \\
\text { of raingauges. }\end{array}$ & $\begin{array}{l}\text { Daily rainfall interpolated from the } \\
\text { dense Meteorological Office network } \\
\text { of raingauges. }\end{array}$ \\
\hline PE data & $\begin{array}{l}\text { PE calculated } \\
\text { from the Penman } \\
\text { equation for short } \\
\text { grass }\end{array}$ & $\begin{array}{l}\text { PE calculated using a modified form of } \\
\text { the Penman-Monteith equation, including } \\
\text { seasonally varying resistance terms } \\
\text { for actual surface cover. }\end{array}$ & $\begin{array}{l}\text { PE calculated from } \\
\text { Penman-Monteith for } \\
\text { short grass. }\end{array}$ \\
& $\begin{array}{l}\text { Not explicitly } \\
\text { modelled, SAAR used } \\
\text { to identify catchments } \\
\text { that experience } \\
\text { evaporation limiting } \\
\text { SMDs. }\end{array}$ & $\begin{array}{l}\text { Two-layer soil moisture store, critical } \\
\text { SMDs defined for vegetation and soil } \\
\text { combinations, modelled on a daily basis. }\end{array}$ & $\begin{array}{l}\text { Simple finite soil } \\
\text { moisture store, defined } \\
\text { by a rooting constant, } \\
\text { modelled on a daily } \\
\text { basis. }\end{array}$ \\
\hline $\begin{array}{l}\text { Catchment losses } \\
\text { of runoff estimates }\end{array}$ & $\begin{array}{l}\text { AE varies linearly } \\
\text { with PE below a } \\
\text { critical SAAR value. }\end{array}$ & $\begin{array}{l}\text { AE varies with PE below a critical SMD } \\
\text { in response to SMDs calculated daily. }\end{array}$ & $\begin{array}{l}\text { AE varies linearly } \\
\text { with PE below a } \\
\text { critical SMD, } \\
\text { calculated daily. }\end{array}$ \\
\hline
\end{tabular}


effective rainfall (1961 to 1990), derived from a $40 \times 40 \mathrm{~km}$ spatial grid.

One criticism of MORECS relates to the relatively coarse network of 156 raingauges used to estimate rainfall, compared to the full Meteorological Office network of more than 6000 stations. The MORECS estimates of rainfall, used to model soil moisture behaviour, are likely to be too coarse to use to estimate runoff. Model $\mathrm{C}$ was developed to examine the benefits of using the complex soil moisture model in MORECS while using SAAR as a better estimate of rainfall. The actual evaporation estimate from MORECS is calculated on a daily basis using the soil moisture model, which progressively reduces the rate of water loss from the potential value to zero as a function of the soil moisture conditions (Hough and Jones, 1997). The structure of Model C is shown in Eqn. (6).

$$
\text { Model C: } \quad A A R D=S A A R-A E
$$

where $A E$ is the average annual actual evaporation estimate from MORECS for the period 1961 to 1990, derived from a $40 \times 40 \mathrm{~km}$ spatial grid. The spatial resolution of both the AE and ERF data could not readily be enhanced to a $1 \times 1 \mathrm{~km}$ grid due to the complex nature of the controlling variables.

\section{Results and discussion}

A comparison of the performance of the four models is shown in Table 4. The results for catchments of low and medium rainfall are illustrated in Fig. 3 whilst Fig. 4 illustrates model performance in high rainfall catchments.

The results show the importance of rainfall estimation for predicting MF in the wettest catchments. Model B uses the coarse estimates of rainfall associated with MORECS, which, although suitable for modelling soil moisture, clearly are not suitable for estimating catchment runoff in high rainfall catchments.

The remaining three models (A, C and the DSMA) use essentially the same rainfall data. In the wettest catchments Model $\mathrm{C}$ has a tendency to under-predict runoff, probably related to an over-estimation of actual evaporation rates due to MORECS climate stations being biased towards lowland stations. Model A and the DSMA model perform similarly in terms of systematic error and the DSMA model is considerably better in terms of random error, indicating that the sequencing of soil moisture deficits is important even in relatively wet catchments.

The steady state water balance model (Model A) performs poorly over the driest UK catchments where runoff is consistently over-estimated as shown in Fig. 3. The model structure does not include a soil moisture store explicitly. Hence, the interactions between SMD and actual

Table 3. Comparison of model performance (best performance shown in bold italics)

\begin{tabular}{|c|c|c|c|c|c|c|c|c|}
\hline \multirow[b]{2}{*}{ Model } & \multicolumn{2}{|c|}{$\begin{array}{l}\text { All catchments } \\
\quad(n=566)\end{array}$} & \multicolumn{2}{|c|}{$\begin{array}{c}S A A R<700 \\
\quad(n=160\end{array}$} & \multicolumn{2}{|c|}{$\begin{array}{c}00<S A A R<1000 \\
(n=213)\end{array}$} & \multicolumn{2}{|c|}{$\begin{array}{l}S A A R>1000 \\
(n=193)\end{array}$} \\
\hline & $B I A S$ & $\begin{array}{l}R M S E \\
\left(m m y r^{-1}\right)\end{array}$ & $B I A S$ & $\begin{array}{l}R M S E \\
\left(m m y r^{-1}\right)\end{array}$ & $B I A S$ & $\begin{array}{l}R M S E \\
\left(m m y r^{-1}\right)\end{array}$ & $B I A S$ & $\begin{array}{l}R M S E \\
\left(m m y r^{-1}\right)\end{array}$ \\
\hline A & -0.054 & 79.2 & -0.198 & 53.5 & -0.011 & 63.5 & 0.017 & 107.6 \\
\hline B & 0.209 & 225.7 & 0.266 & 80.1 & 0.168 & 122.2 & 0.207 & 357.0 \\
\hline $\mathrm{C}$ & 0.191 & 109.5 & 0.275 & 75.6 & 0.179 & 92.0 & 0.135 & 145.0 \\
\hline DSMA & 0.019 & 46.8 & 0.027 & 38.9 & 0.009 & 47.7 & 0.024 & 51.4 \\
\hline
\end{tabular}

Table 4. Factorial Standard Error (FSE) resulting from a regression of $L O G(A A R D)_{\mathrm{OBS}}$ against LOG(AARD) ${ }_{\text {PRED }}$

\begin{tabular}{lcccc}
\hline Model & All catchments & SAAR $<700$ & $700<$ SAAR $<1000$ & $S A A R>1000$ \\
\hline A & 1.229 & 1.362 & 1.163 & 1.103 \\
B & 1.331 & 1.374 & 1.258 & 1.256 \\
C & 1.212 & 1.345 & 1.166 & 1.076 \\
DSMA & $\mathbf{1 . 1 6 5}$ & $\mathbf{1 . 2 5 9}$ & $\mathbf{1 . 1 3 4}$ & $\mathbf{1 . 0 5 6}$ \\
\hline
\end{tabular}


M.G.R. Holmes, A.R.Young, A. Gustard and R. Grew

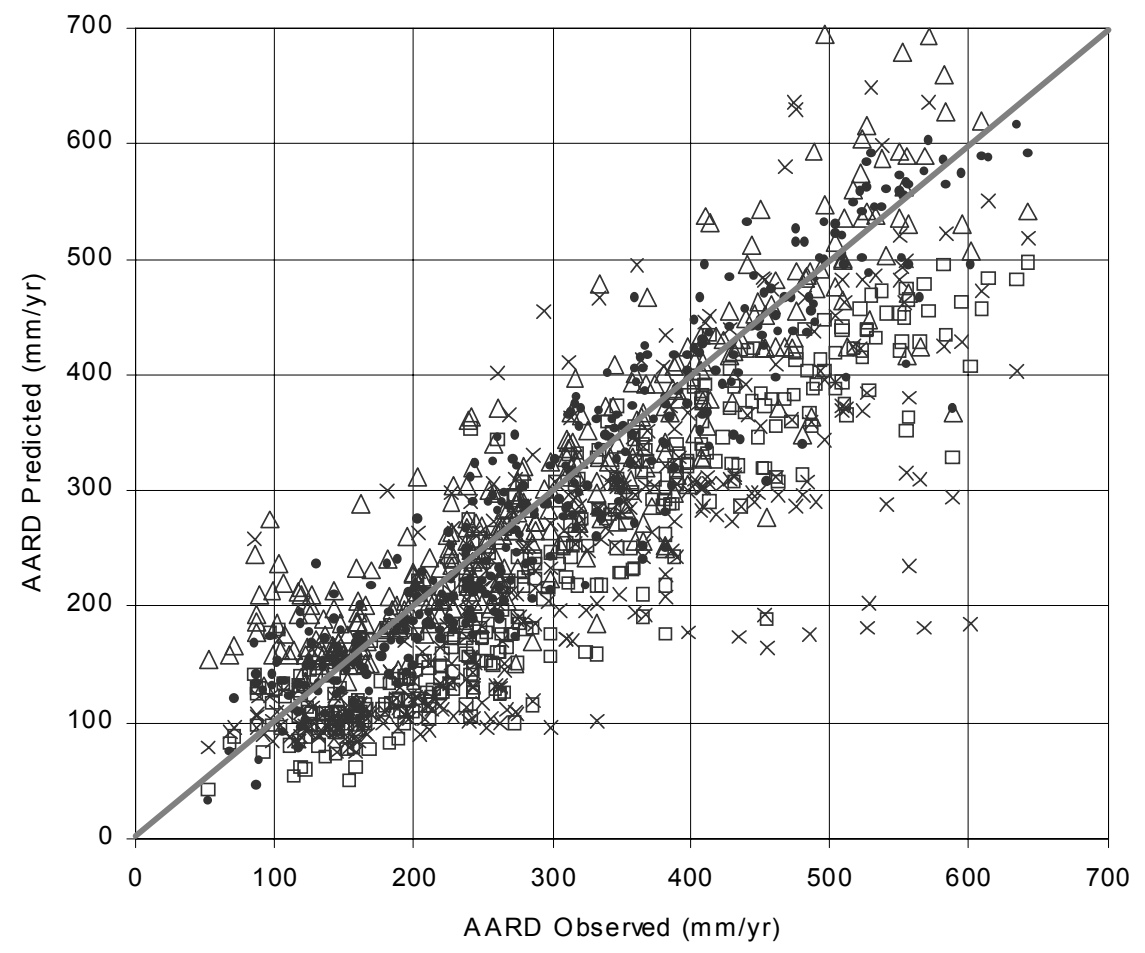

$\triangle$ Model A $\times$ Model B $\square$ Model C . DSMAM

Fig. 3. Performance of models over low rainfall catchments (SAAR $\left.<1000 \mathrm{mmyr}^{-1}\right)$

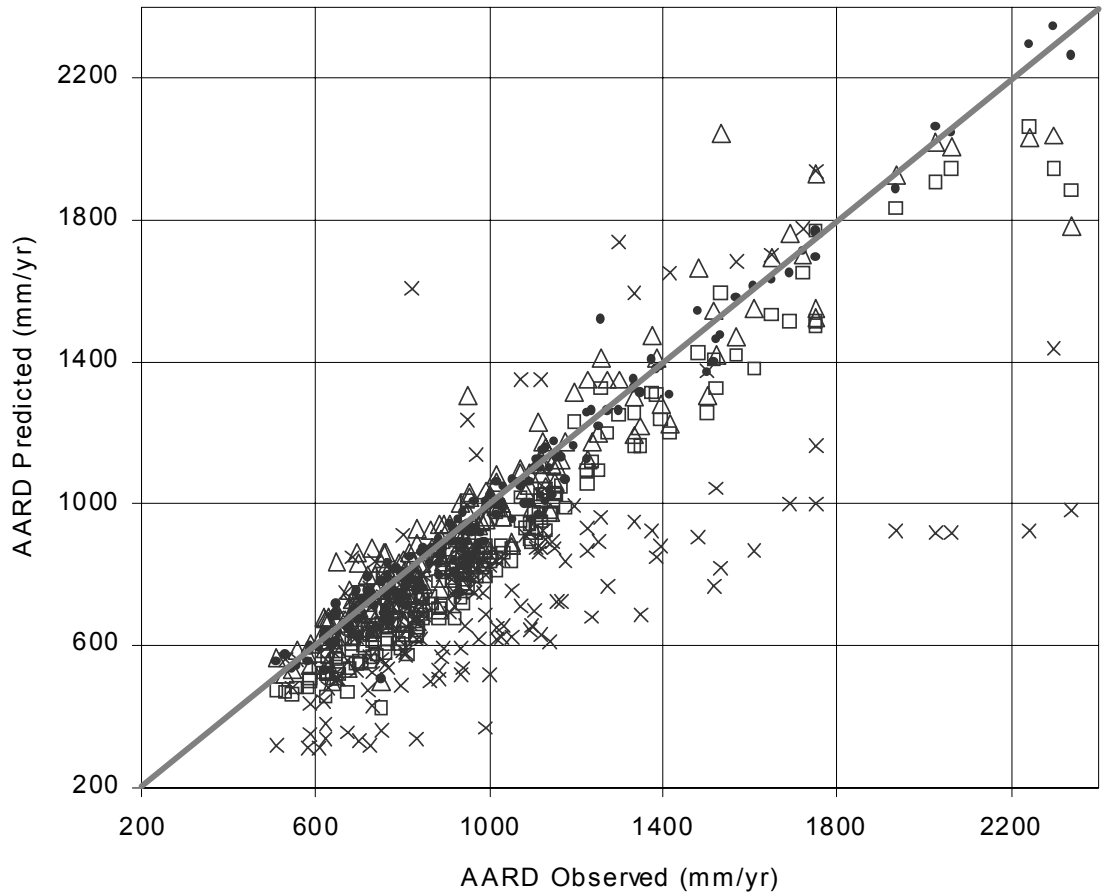

$\triangle$ Model A $\times$ Model B $\square$ Model C. DSMAM

Fig. 4. Performance of models over high rainfall catchments (SAAR $\left.>1000 \mathrm{mmyr}^{-1}\right)$ 
evaporation rates cannot be replicated. Furthermore, average annual rainfall is used to determine whether significant soil moisture deficits occur within a catchment, whereas it is the progressive daily or sub-daily development of soil moisture deficits that defines these points.

Models B and C could be expected to perform similarly in low rainfall catchments, where the differences in rainfall estimation methods will be less, and better than Model A over dry catchments due to the inclusion of the MORECS soil moisture models; however, this was not confirmed by the results. The observed consistent under-prediction of runoff in dry catchments by MORECS was also found by Jolley et al. (1996). This supports suggestions made by Gardner and Field (1983) and Ragab et al. (1997) that MORECS tends to over-estimate observed soil moisture deficits and hence would over-predict actual evaporation rates, leading to an underestimation of effective rainfall. Model A has been calibrated against the variable of interest, catchment runoff and this outweighs the benefits associated with the dynamic, daily soil moisture models within MORECS.

The DSMA model was shown to perform best over the entire data set of catchments as well as over the driest UK catchments. The benefits of adopting a daily time step model enable the impact of soil moisture deficits on runoff to be modelled successfully. The one parameter model for reducing evaporation below the potential rate in response to soil moisture conditions on a daily basis, is successful at modelling long term runoff. The DSMA model performance is superior to the MORECS based models primarily due to the fact that it has been calibrated against streamflow records rather than soil moisture data, which compensates for a more simplistic soil moisture model.

\section{Conclusions}

The topography and climatic conditions of the UK combine to create two main issues for the application of water balance models. In the wetter western and northern regions, the network of climate stations is relatively sparse and, in these mountainous areas, the rainfall is highly variable. Therefore, the estimation of precipitation inputs to the water balance equation is a significant source of uncertainty, particularly in small catchments. However, the average annual rainfall is relatively high in these areas so that significant, evaporation-limiting soil moisture deficits do not occur regularly and the estimation of actual evaporation is simplified.

In the drier southern and eastern regions of the UK, the spatial distribution of rainfall is generally more homogeneous and the climate station network is generally more dense, hence catchment rainfall may be estimated with more certainty. However, net rainfall is less and potential evaporation rates are higher so that significant soil moisture deficits develop on a regular basis. Therefore, estimation of actual evaporation is more complex as the interaction between climatic conditions and soil moisture deficit development must be considered.

The development of a semi-distributed regionalised model for estimating MF that accounts for the impact of progressive soil moisture deficits represents a considerable advance in MF estimation in the UK. Calibration of the model with stream flow records has proved more important than a complex soil moisture model structure. The DSMA model predictions of MF were superior to existing models across all catchments, specifically in low rainfall areas. The importance of improving MF estimation in dry catchments is very real since approximately $27 \%$ of the land area of the UK receives less than $700 \mathrm{~mm}$ of rainfall per year. Therefore, the estimation of a basic resource measure such as MF is essential for effective UK water resource management on a national basis.

The ability to quantify the impacts of climate change on water resource availability is becoming increasingly important across the globe. The dynamic modelling approach adopted in the DSMA model is well suited to this task and enables simulation of changes to the volume and spatial distribution of rainfall; changes to potential evaporation rates due to increases in solar energy input and modifications to vegetation cover as this effects soil moisture behaviour. These types of scenario analysis are not possible using traditional water balance approaches.

This study did not undertake detailed uncertainty analysis of the sensitivity of the performance of the DSMA model to variability of the RC parameter. Further research to quantify the impact of poorly represented LANDHOST classes on the overall performance of the DSMA model is required as well as studies of the impact of uncertainties in the daily climatic data.

\section{Acknowledgements}

The research described in this paper was carried out at CEHWallingford (formerly the Institute of Hydrology) funded by the Natural Environment Research Council and the Environment Agency (Research and Development Project W6-057, Project Manager Dr. Robert Grew).

\section{References}

Arnell, N.W., 1999. Climate change and global water resources. Global Environ. Change, 9, S31-S49. 
Beven, K., 1989. Changing Ideas in Hydrology: The Case of Physically-Based Models. J. Hydrol., 105, 157-172.

Boorman, D.B., Hollis, J.M. and Lilly, A., 1995. Hydrology of soil types: a hydrologically-based classification of the soils of the United Kingdom. Report 126. Institute of Hydrology. Wallingford, UK.

Fuller, R.M., Groom, G.B. and Jones, A.R., 1994. The land cover map of Great Britain: An automated classification of Lansat thematic mapper data. Photogramm. Eng. Remote Sensing, 60, 553-562.

Gardner, C.M.K. and Field, M., 1983. An evaluation of the success of MORECS, a meteorological model, in estimating soil moisture deficits. Agr. Fores. Meteorol. 29, 269-284.

Grindley, J., 1970. Estimation and mapping of evaporation. IAHS Publication No. 1, 200-213.

Gustard, A., Bullock, A. and Dixon, J.M., 1992. Low flow estimation in the United Kingdom. Report 108. Institute of Hydrology. Wallingford, UK.

Holmes, M.G.R., Young, A. R., Grew, R. and Gustard, A.,2002. A Region of Influence approach to predicting Flow Duration Curves within ungauged catchments. Hydrol. Earth Syst. Sci., 6, 721-731.

Hough, M.N. and Jones, R.J.A., 1997. The United Kingdom Meteorological Office rainfall and evaporation calculation system: MORECS version 2.0 - an overview. Hydrol. Earth Syst. Sci., 1, 227-239.

Hough, M.N., Palmer, S.G., Weir, A., Lee, M.J. and Barrie, I.A., 1995. The Meteorological Office rainfall and evaporation calculation system: MORECS version 2.0. An update to Hydrological Memorandum 45. Meteorological Office, Bracknell, UK.

Institute of Hydrology, 1980. Low Flow Studies Report. Institute of Hydrology. Wallingford. UK.

Jolley, T.J. and Wheater, H.S., 1996. A large-scale grid-based hydrological model of the Severn and Thames catchments. $J$. CIWEM., 10, 253-262.

Jones, S.B., 1983. The estimation of catchment average point rainfall profiles. Report 87. Institute of Hydrology, Wallingford, UK.

Manley, R.E., 1978. The use of a hydrological model in water resources planning. Proc. Inst. Civil Eng., Part 2, 65, 223-235.

Monteith, J.L., 1965. Evaporation and environment. 19th Symposia of the Society for Experimental Biology. Cambridge, Cambridge University Press, 19, 205-234.
Moore, R.J., 1985. The probability-distributed principle and runoff production at point and basin scales. Hydrolog. Sci. J., 30, $273-$ 297.

Penman, H.L., 1948. Natural evaporation from open water, bare soil and grass. Proc. R. Soc. London, Ser. A, 193, 120-145.

Penman, H.L., 1949. The dependence of transpiration of weather and soil conditions. . Soil Sci., 1, 74-89.

Penman, H.L., 1950. Evaporation over the British Isles. Quart. J. Roy. Meteorolog. Soc., 76, 372-383.

Ragab, R., Finch, J. and Harding, R., 1997. Estimation of groundwater recharge to chalk and sandstone aquifers using simple soil models. J. Hydrol., 190, 19-41.

Russell, G.L. and Miller, J.R., 1990. Global river runoff calculated from a global atmospheric general circulation model. J. Hydrol., 155, 301-323.

Shaw, E.M., 1988. Hydrology in Practice. Ed. 2. Van Nostrand Reinhold (International), London. UK.

Thompson, N., Barrie, I.A. and Ayles, M., 1981. The Meteorological Office rainfall and evaporation calculation system: MORECS. Meteorological Office, Bracknell, UK.

Thornthwaite, C.W., 1948. An approach toward a rational classification of climate. Geogr. Rev., 38, 55-94.

Turc, L., 1954. Calcul du bilan de l'eau evaluation en fonction des precipitations et des temperatures (Calculation of the water balance: Evaluation of the function of precipitation and temperature). IAHS Rome Symposium 111, Publication No. 38 , 13-49.

Turc, L., 1955. Le bilan d'eau des sols. Relations entre les precipitations, l'evaporation et l'ecoulement (The groundwater balance: Relationships between precipitation, evaporation and runoff). Ann. Agron., 6, 5-131.

Wallace, J.S., 1994. Calculating evaporation: resistance to factors. Agr. Forest Meteorol., 73, 353-366.

Young, A.R., 2000. Regionalising a daily rainfall-runoff model within the United Kingdom. Southampton University. Unpublished Ph.D.

Young, A.R., Gustard, A., Bullock, A., Sekulin, A.E. and Croker, K.M. 2000. A river network based hydrological model for predicting natural and influenced flow statistics at ungauged sites. Sci. Total Environ., 251/252, 293-304. 